\title{
Neural Network Based Estimation of Service Life of Different Metal Culverts in Arkansas
}

\author{
Zahid Hossain $\left(\mathbb{D},{ }^{1}\right.$ MdAriful Hasan $\mathbb{D}^{2},{ }^{2}$ and Rouzbeh Ghabchi $\mathbb{i D}^{3}$ \\ ${ }^{1}$ Civil Engineering, Arkansas State University, P.O. Box 1740, Engineering LSW 246, Jonesboro, AR 72467, USA \\ ${ }^{2}$ Arkansas State University, P.O. Box 1740, Engineering LSW 246, Jonesboro, AR 72467, USA \\ ${ }^{3}$ Civil Engineering, South Dakota State University, Crothers Engineering Hall 132, Box 2219, Brookings, SD 57007, USA
}

Correspondence should be addressed to Zahid Hossain; mhossain@astate.edu

Received 31 October 2021; Accepted 9 December 2021; Published 4 January 2022

Academic Editor: Juan Bojórquez

Copyright (c) 2022 Zahid Hossain et al. This is an open access article distributed under the Creative Commons Attribution License, which permits unrestricted use, distribution, and reproduction in any medium, provided the original work is properly cited.

\begin{abstract}
The Arkansas Department of Transportation (ARDOT) uses different types of metal culverts and cross-drains. Service lives of these culverts are largely influenced by the corrosion of the metals used in these culverts. Corrosion of metallic parts in any soilwater environment is governed by geochemical and electrochemical properties of the soils and waters. Many transportation agencies including ARDOT primarily focus on investigating the physical and mechanical properties of soils rather than their chemical aspects. The main objective of this study is to analyze the geotechnical and geochemical properties of soils in Arkansas to estimate the service lives of different metal pipes in different conditions. Soil resistivity values were predicted after analyzing the United States Department of Agriculture (USDA) soil survey data using neural network (NN) models. The developed NN models were trained and verified by using laboratory test results of soil samples collected from ARDOT, and survey data were obtained from the USDA. The service lives of metal culverts were then estimated based on the predicted soil properties and water quality parameters extracted from the data acquired from the Arkansas Department of Environmental Quality (ADEQ). Finally, Geographic Information System-based corrosion risk maps of three different types of metal pipes were developed based on their estimated service lives. The developed maps will help ARDOT engineers to assess the corrosion potential of the metal pipes before starting the new construction and repair projects and will allow using proper culvert materials to maximize their life spans.
\end{abstract}

\section{Introduction}

Metal culverts or pipes are frequently used in Arkansas for different highway drainage structures and irrigation purposes. These culverts are susceptible to significant corrosion. Arkansas has a history of culvert failures and corrosion of the metal culverts was found to be the major reason behind these failures. The Arkansas Department of Transportation (ARDOT) spends a significant amount of money in replacing and installing different types of culverts for crossdrains every year. In 2018, the ARDOT allocated about US $\$ 3.5 \mathrm{M}$ for the installation of new and replacement of existing metal pipe culverts [1]. In the coming years, the ARDOT expects to construct and install more metal culverts. The selection of appropriate metallic materials for these culverts at different construction sites within the state can save future investment and minimize maintenance costs.

The ARDOT's 2014 Standard Specifications for Highway Construction document does not provide enough details about the measures needed to be taken to reduce losses due to corrosion [1]. In Section 601 of the ARDOT's 2014 Standard Specifications for Highway Construction, the types of metal culverts that can be used in Arkansas are enlisted. According to the ARDOT specifications, zinc coated (galvanized) corrugated steel pipes, aluminum coated corrugated steel pipes, aluminum-zinc alloy coated corrugated steel pipes, corrugated aluminum pipes, asphalt coated corrugated metal pipes, polymer precoated metallic coated corrugated steel pipe culverts, and smooth lined polymer precoated metallic coated corrugated steel pipes can be used 
[1]. The corrosion rates of these pipes depend on the materials used in these pipes and their physiochemical properties, type of coatings, properties of soils around the pipes, the quality of surface water passing through the pipes, quality of groundwater, ambient temperature, and other environmental factors. Highly corrosive surface water, abrasive bed materials, and corrosive groundwater can also influence the corrosion of the culverts. Several studies have been conducted in other states to analyze the service life of metal culverts and to prepare risk maps. However, the ARDOT does not have detailed information about the probable spatial distribution of corrosion rates and the expected service life of different metals. Also, no specific guidelines exist for pipe material selection and their installation and/or replacement schedule in Arkansas.

The National Resource Conservation Services (NRCS) used the Survey Geographic Database (SSURGO) and mapped the uncoated steel corrosion risk potentials as low, moderate, and high based on different indicator variables. The NRCS used drainage class and texture of soils, the total acidity of the soil, soil resistivity at saturation, and conductivity of saturated extract for risk classification. The agency has defined the "low" corrosion risk potential when the soil is well-drained and contains coarse-textured particles in combination with a total acidity less than $8 \mathrm{meq} /$ $100 \mathrm{~g}$, a resistivity at saturation of at least $5000 \mathrm{ohms} / \mathrm{cm}$, and conductivity of saturated extract less than $0.3 \mathrm{mmhos} \mathrm{cm}^{-1}$. Similarly, "moderate" corrosion risk potential is defined as when the soil is moderately well-drained, in general, with moderately coarse-textured soils, having a total acidity between 8 and $12 \mathrm{meq} / 100 \mathrm{~g}$, soil resistivity at saturation between 2000 and $5000 \mathrm{ohms} / \mathrm{cm}$, and soil conductivity of saturated extract between 0.3 and $0.8 \mathrm{mmhos} \mathrm{cm}^{-1}$. Finally, "high" corrosion risk potential is considered mostly for finetextured soils with varied draining conditions, along with a minimum total acidity of $12 \mathrm{meq} / 100 \mathrm{~g}$, a resistivity at saturation of fewer than $2000 \mathrm{ohms} / \mathrm{cm}$, and conductivity of saturated extract greater than or equal to $0.8 \mathrm{mmhos} \mathrm{cm}^{-1}$ (NRCS 2018, [2], and [3]). In this study, risk categories are divided into five different classes based on soil resistivity and $\mathrm{pH}$ criteria, and they are applied for mapping purposes.

Tiwari and Manning [4] have developed metal corrosion risk maps for the southern parts of Louisiana. These researchers categorized corrosion potentials into four different types like "mildly corrosive," "corrosive," "highly corrosive," and "extremely corrosive," based on the expected average life of metal pipes. These researchers used doubly weighted $25 \times 12$ matrix to categorize the risk potentials based on the $\mathrm{pH}$ and resistivity of soil. The risk matrix was subdivided based on the studies conducted by the Colorado Department of Transportation and Louisiana Department of Transportation and Development and the SSURGO database was used for extracting soil conductivity and $\mathrm{pH}$ data.

The main objective of this study is to develop corrosion maps for Arkansas based on secondary data analysis, laboratory test results, neural network (NN) modeling for predicting soil resistivity, and estimation of service life. Relevant literature and guidelines have been reviewed to analyze the best options of the targeted index parameters based on the available data sources and specific gaps were assessed and addressed accordingly. In this study, galvanized steel pipes (plain), corrugated aluminum (type II) steel pipes, and corrugated aluminum pipe were considered for service life estimations.

\section{Methodology}

The American Iron and Steel Institute (AISI), the National Corrugated Steel Pipe Association (NCSPA), California Department of Transportation (CALTRANS), Florida Department of Transportation, and a few other agencies in the United States have estimated the service life of different metal culverts for different locations. These agencies have pointed out that resistivity, $\mathrm{pH}$, chloride, sulfate, moisture content, dissolved gases, and bacterial activities in soil and water can influence the service life of a metal pipe. However, most of the agency-developed methods for estimating the service life of metal pipes are based on soil resistivity, soil $\mathrm{pH}$, water resistivity, and water $\mathrm{pH}$. Again, both the outer and inner sides of metal culverts are vulnerable to corrosion. Corrosion in the outer side of the culverts is mainly governed by the soil or backfill material properties and groundwater quality parameters. On the other hand, the inner side corrosion of the culverts is primarily governed by the drainage water quality parameters and abrasive properties of sediments passing through the culverts [5]. The ARDOT does not have details of the spatial variability of these parameters across the state. As a result, an extensive literature review was carried out to estimate the service life and develop metal corrosion maps. In this process, relevant data sources were identified, and relevant data and soil samples were collected. After the literature review, soil resistivity was found as a missing critical parameter in the ARDOT's typical soil investigation reports. So, an NN-based prediction model was developed to predict soil resistivity based on soil properties provided in the SSURGO and laboratory test results of collected soil samples. Finally, based on the laboratory analysis of collected soil data and secondary data preprocessing and analysis, service lives of metal culverts in different locations of the state were estimated and mapped. A detailed flowchart of the steps involved in this project is presented in Figure 1.

2.1. Secondary Data Collection and Preprocessing. The ARDOT has a database of geotechnical reports from previous construction projects. However, the ARDOT does not have enough data related to electric resistivity and electric conductivity of soils. The United States Department of Agriculture (USDA) has conducted extensive soil surveys within the United States and has documented all the data in an accessible format. The SSURGO database has extensive extractable data comprised of important soil physical and chemical properties (NRCS 2018 and [2]). It has relevant data in the form of 68 different Microsoft-Access (MSAccess) datasets for all 75 counties in Arkansas. Using Soil Data Viewer, an add-ins software, data were extracted as 


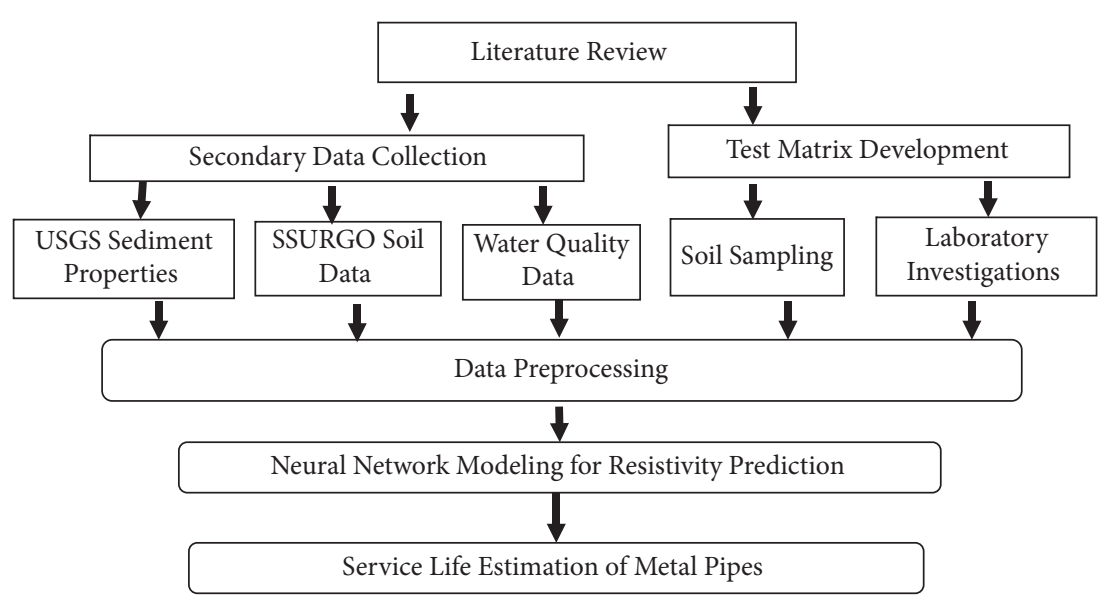

FIGURE 1: Flowchart of the study methodology.

polygon shapefiles of different parishes with corresponding soil properties.

In this study, the Soil Data Viewer tool was added to ArcMap 10.6.1 for the SSURGO data extraction. Feature classes of twenty-one different soil parameters were extracted and merged to create a shapefile related to all the counties in the state. These features were selected based on the factors that are important for corrosion predictions and referred to in different works of literature. The features selected from the SSURGO are as follows: potential risks of corrosion in concrete (categorized as high, moderate, and low), potential risk of corrosion in uncoated steel (categorized as high, moderate, and low), equivalent calcium carbonate content (percent of carbonates, by weight, in the fraction of soil mass which are less than $2 \mathrm{~mm}$ in size), cation exchange capacity (CEC-7), effective cation-exchange capacity (ECEC), electric conductivity (EC), gypsum (percent by weight, of hydrated calcium sulfates in the $<20 \mathrm{~mm}$ fraction of soil), $\mathrm{pH}$, sodium adsorption ratio (SAR), liquid limit, organic matter, percent clay (soil particles that are less than 0.002 millimeter in diameter), percent sand (soil particles that are 0.05 millimeter to 2 millimeters in diameter), percent silt (soil particles that are 0.002 to 0.05 millimeter in diameter), plasticity index, saturated hydraulic conductivity (micrometers per second), AASHTO soil classification, drainage class, depth of water table, flooding frequency class(categorized as none, very rare, rare, occasional, frequent, and very frequent), and ponding frequency class (categorized as none, rare, occasional, and frequent) $[2,6]$. After collecting all the soil data from SSURGO, a series of geoprocessing tasks was completed by using ArcMap's toolbox and "ArcPy" module commands to clean and merge them. After merging all the data of all 75 counties, having a total of 334,102 parishes, in Arkansas, all the fields were renamed for keeping the attribute table clean and easily exportable. A summary of the extracted numerical datasets is presented in Table 1. All the data presented in Table 1 are summarized based on the extracted data of the 334,102 parishes that are within the state of Arkansas.

After completion of data extraction, all the polygon layers were dissolved into one layer. The initial geographic coordinate reference (GCS_North_American_1983) data for all polygons were also converted to the projected coordinate system (NAD_1983_UTM_ZONE_15N). Later on, this projected coordinate system was used for applying all the geospatial interpolations. Geometric features, $X$ and $Y$ coordinates of the center of each polygon, were also added to the attribute table. The final polygon shapefile was named "AR_Dissolved_SSURGO.shp," which had a total of 334,102 polygons. The dataset, "AR_Dissolved_SSURGO.dBase" file, was extracted as a Microsoft Excel spreadsheet. The data were then saved in a different place for further processing and use in the MATLAB programs.

The ADEQ also has an extensive dataset of water quality parameters from different monitoring stations within the state. These datasets are extractable in the Microsoft Excel spreadsheet format. In this study, water $\mathrm{pH}$ and total dissolved solid data of the 75 counties were collected and merged with location details. Later the extracted datasets were transformed into point feature layers based on the locations of the stations [7].

2.2. Laboratory Investigations. The SSURGO database has a combination of geotechnical and geochemical parameters of soils. Secondary data collected from the SSURGO have both geotechnical and geochemical data. For gathering additional data and boosting the observation and prediction model development, soil samples were collected from different ongoing construction projects in ARDOT Districts 10 and 02 . District engineers were contacted and with their help, 22 soil samples were collected. Geographic locations of the collected soil samples were also collected through ARDOT engineers. Soil resistivity, $\mathrm{pH}$, grain size distribution, Atterberg limits, and specific gravities of the collected soil samples were determined in the laboratory by following ASTM G57, ASTM G51, ASTM D422, ASTM D4318, and ASTM D854 methods, respectively. The description of the soil samples with latitude and longitude of the sampling points, laboratory measurement of soil $\mathrm{pH}$, and resistivity values are summarized in Table 2. 
TABLE 1: Summary of SSURGO data of Arkansas.

\begin{tabular}{|c|c|c|c|c|}
\hline Field & Min. & Max. & Mean & Standard deviation \\
\hline $\mathrm{CaCo}_{3}$ & 0.00 & 14.00 & 0.06 & 0.45 \\
\hline Cation exchange capacity (meq/10 g) & 0.00 & 57.50 & 7.38 & 10.18 \\
\hline Effective cation exchange capacity (meq/10 g) & 0.00 & 56.70 & 10.71 & 8.28 \\
\hline Electric conductivity $\left(\mathrm{mmhos} \mathrm{cm}^{-1}\right)$ & 0.00 & 8.60 & 0.20 & 0.56 \\
\hline Gypsum & 0.00 & 3.00 & 0.02 & 0.21 \\
\hline $\mathrm{pH}$ & 4.30 & 8.30 & 5.35 & 0.65 \\
\hline Sodium absorption ratio & 0.00 & 16.50 & 0.09 & 0.78 \\
\hline Liquid limit & 4.90 & 85.00 & 36.75 & 11.20 \\
\hline Organic matter content & 0.02 & 4.40 & 0.66 & 0.43 \\
\hline Clay $(\%)$ & 3.50 & 73.00 & 28.50 & 11.67 \\
\hline Sand $(\%)$ & 1.50 & 95.00 & 31.02 & 19.63 \\
\hline Silt $(\%)$ & 0.60 & 77.40 & 40.45 & 16.30 \\
\hline Plasticity index & 0.00 & 58.70 & 16.92 & 8.80 \\
\hline Hydraulic conductivity (micrometers per second) & 0.14 & 92.00 & 9.51 & 12.84 \\
\hline Depth of water table $(\mathrm{cm})$ & 0.00 & $>201$ & 118.18 & 76.52 \\
\hline
\end{tabular}

TABLE 2: Resistivity and $\mathrm{pH}$ testing results of soils.

\begin{tabular}{|c|c|c|c|c|c|}
\hline ID & Description & Latitude & Longitude & $\mathrm{pH}$ & $R_{\min }(\mathrm{ohm}-\mathrm{cm})$ \\
\hline D10-01 & Job no: BR1610 & 35.830528 & -90.764481 & 6.44 & 10682.25 \\
\hline D10-02 & Monette, AR & 35.890578 & -90.324728 & 6.69 & 11364.82 \\
\hline D10-03 & Job no: BB1006 & 35.984167 & -89.875556 & 6.44 & 2271.28 \\
\hline D10-04 & Job no: 100760 & 35.611944 & -90.203889 & 7.23 & 1107.73 \\
\hline D10-05 & Job no: 100654 & 35.903611 & -90.291944 & 6.49 & 8077.66 \\
\hline D10-06 & Job no: 100740 & 35.888889 & -89.911667 & 6.70 & 1339.86 \\
\hline D10-07 & Job no: 100653 & 35.903056 & -90.237222 & 6.44 & 5395.69 \\
\hline D10-08 & Job no: 100708 & 35.997157 & -90.562616 & 7.28 & 6392.07 \\
\hline D10-09 & Job no: 100708 & 36.056047 & -90.621886 & 7.04 & 7305.18 \\
\hline D10-10 & Job no: 100708 & 35.830966 & -90.512811 & 6.08 & 6933.06 \\
\hline D10-11 & Job no: 100708 & 35.830966 & -90.512811 & 7.03 & 6891.44 \\
\hline D10-12 & S Caraway Road, Jonesboro & 35.800625 & -90.678611 & 8.33 & 9187.68 \\
\hline D02-01 & Job no: GF 0270 & 33.654583 & -91.211944 & 7.80 & 4028.17 \\
\hline D02-02 & Job no: 020534 & 33.134944 & -91.855556 & 6.48 & 16480.59 \\
\hline D02-03 & Job no: 20584 & 34.100817 & -92.001944 & 5.06 & 9710.39 \\
\hline D02-04 & Job no: BB0203 & 34.221944 & -92.074444 & 6.49 & 2168.77 \\
\hline D10-SR01 & S Caraway Road, Jonesboro & 35.802683 & -090.67863 & 6.40 & 9234.50 \\
\hline D10-SR02 & S Caraway Road, Jonesboro & 35.792397 & -090.678437 & 7.26 & 6770.66 \\
\hline D10-SR03 & S Caraway Road, Jonesboro & 35.778245 & -090.679274 & 5.66 & 7608.75 \\
\hline D10-SR04 & S Caraway Road, Jonesboro & 35.761323 & -090.679531 & 5.91 & 3448.44 \\
\hline D10-SR05 & S Caraway Road, Jonesboro & 35.781553 & -090.679059 & 4.78 & 3569.53 \\
\hline D10-SR06 & S Caraway Road, Jonesboro & 35.793668 & -090.678716 & 6.21 & 34554.10 \\
\hline
\end{tabular}

All the data obtained from laboratory investigation were imported to ArcGIS as "soil_sample_data" data. The soil sample dataset had sampling location, sample ID, $\mathrm{pH}$, resistivity, specific gravity, liquid limit, plasticity index, percent sand, percent clay, and percent silt data only. Additional data related to the soil samples were added to the dataset based on the SSURGO data available for the closest geographical location. In the next stage, laboratory investigation data were extracted as a point feature class, "soil_sample_data." The joined data were finally converted to an Excel-readable format.

2.3. Soil Resistivity Prediction. For developing a soil resistivity prediction model, the exported datasheet (in spreadsheet format) with all dissolved values was further cleaned by removing duplicate rows irrespective of their metadata.
After cleaning 334,102 rows, only 1,927 rows of data were found to be unique and meaningful. However, all of those rows did not have values for EC. Therefore, the dataset was filtered and reduced to rows having EC values. The new dataset having EC values was comprised of 152 rows. Then, the EC values were converted to resistivity values with a conversion factor and the experimental results of 16 soil samples were added to the 152 rows of data obtained from the SSURGO database. Finally, 168 datasets were used to train a shallow neural network fitting tool.

Based on the experience of initial data classification and principal component analysis results, ten parameters were selected for the prediction of soil resistivity. The selected parameters were cation exchange capacity, effective cation exchange capacity, $\mathrm{pH}$, liquid limit, percent organic content, percent clay content, percent sand content, percent silt content, plasticity index, and hydraulic conductivity. After 
several trials, the Bayesian regularization-based "trainbr," a MATLAB function, was selected for developing the neural network models. In the case of selecting several hidden layers and the number of neurons, a simplified approach was used. According to Erzin et al. [8], the maximum number of neurons that can be used for any given number of variables (I) is $2 I+1$. Based on Erzin et al. [8], for ten predictors, a maximum of 21 neurons were considered for training the model. A random process was used for the selection of the datasets for training, validation, and testing at ratios of $75 \%$, $5 \%$, and $20 \%$, respectively. A shallow neural network with having 10 hidden neurons was found to be the best applicable prediction model for the datasets used in this study. A MATLAB function was generated based on the best-performed model, which was finally used to predict the soil resistivity for the rest of the datasets. A summary of performance indicators after training the dataset with different structures of hidden layers is shown in Table 3 .

The coefficient of determination $\left(R^{2}\right)$ is a measurement of the performance indicator of any regression model. The training and testing results of the neural network show that one hidden layer with ten neurons has the highest value of $R$ (Table 3). A hidden layer with eight neurons also has comparatively better training and testing performance. From Table 3, it is evident that an increase in the number of neurons resulted in a deterioration in the performance of the model. In the cases of multilayer hidden structures, the model having a two-layer structure with seven neurons in the first layer and three neurons in the second layer was found to exhibit an acceptable performance. However, with an increase in the number of layers and number of neurons, the overall performance was found to reduce. Therefore, based on the performance evaluations, a simple model with one hidden layer of ten neurons was selected as the final model. The $R^{2}$ value of the model in the training and overall phases is $0.99(R=0.99)$ and $0.57(R=0.75)$, respectively. This is a relatively acceptable performance for estimating the soil resistivity of a location lacking any physical resistivity measurements. In other words, the developed NN model can be used to predict soil resistivity by using only the SSURGO data as input parameters.

2.4. Service Life Estimation. The American Iron and Steel Institute (AISI), the National Corrugated Steel Pipe Association (NCSPA), and many transportation agencies have developed their methods for evaluation of service life of different culverts [5]. For galvanized steel pipes (GSP), the "California Method" is widely accepted and used among practitioners when no prior knowledge of the study site is available. The AISI, the Florida Department of Transportation (FDOT), the Federal Lands Highway (FLH), the Colorado Department of Transportation, the NCSPA, and the Utah DOT have also developed their methods of evaluating the service life of GSPs. Most of the methods including the "California Method" use resistivity and $\mathrm{pH}$ for evaluation of the service life of GSPs. The graphical form of the "California Method" is shown in Figure 2(a) [9], and it has been used for estimating the service life of GSPs in this study. Aluminized steel (type II) pipe is another common type of culvert used by the ARDOT. The FDOT developed a method based on resistivity, gage thickness, and $\mathrm{pH}$ to estimate the service lives of aluminized steel culverts, as presented in Figure 2(b). Aluminum pipe is a material that is commonly used by different state agencies. The FDOT also developed a method to estimate the service life of this type of culvert. A graphical representation of this method is shown in Figure 2(c) $[5,10,11]$. The methods developed by FDOT [10] have been used for the estimation of the service life of aluminized steel and aluminum pipes in this study.

As mentioned earlier, corrosion in the inner side and outer side of the metal pipe is mainly controlled by the water quality parameters and soil or backfill parameters. Part of the pipe connected to the soil bed is more susceptible to corrosion of easier electric passage. For this reason, multiple studies have recommended the use of both the electric resistivity and $\mathrm{pH}$ of soil and water for the estimation of service life. In the current study, the electric resistivity and $\mathrm{pH}$ of both soil and water were considered, and the minimum estimated service life (in years) was considered as the expected service life of that pipe. To this end, $\mathrm{pH}$ values available in the SSURGO database and the soil resistivity predicted from the developed neural network model were used. On the other hand, $\mathrm{pH}$ values of water available in the ADEQ dataset were used for estimating the pipe service lives. The resistivity (in ohm-cm) of water was estimated from total dissolved solids ( $\mathrm{mg} / \mathrm{l})$, available in the ADEQ dataset, by applying a correlation developed by Rusydi [12].

For mapping purposes, the entire state of Arkansas was divided into rasters (size of each raster $250 \mathrm{~m} \times 250 \mathrm{~m}$ ). Then the nearest neighbor method was applied to assign water resistivity and $\mathrm{pH}$ to individual point features. The ArcGIS geoprocessing tool was used for this purpose. Later, the raster features were converted to point features and the Empirical Bayesian Kriging (EBK) technique was applied to develop the interpolated map of predicted service life for different locations in Arkansas. Three different maps were prepared for the three types of selected metal pipes. For comparative analysis, a 16-gage pipe was selected for estimation of the service lives of all three metal pipes. All three methods are based on using resistivity and $\mathrm{pH}$ values of the surrounding soil and surface water. Therefore, service lives can be estimated based on the detailed graphs shown in Figure 2. These methods predict the service lives (in years) of the metal pipes, which vary linearly or nonlinearly with the logarithmic scale of resistivity of surrounding media for a particular range of $\mathrm{pH}$. When the $\mathrm{pH}$ range varies, the response curves shift. In all three cases, the response curves were found to have positive slopes shifting towards their ordinates with an increase in $\mathrm{pH}$ values. Aluminum pipes were found to be less sensitive to resistivity values when compared with the other two types of metal pipes.

\section{Research Outcomes}

3.1. $p H$. Based on the data extracted from the SSURGO database, it was observed that the soil $\mathrm{pH}$ values varied from 4.3 to 8.3 with an average value of 5.4 and a standard 
TABLE 3: Shallow NN training results for prediction of the soil resistivity data after including laboratory test results.

\begin{tabular}{|c|c|c|c|c|c|c|c|c|c|c|}
\hline Training function & Trainbr & Trainbr & Trainbr & Trainbr & Trainbr & Trainbr & Trainbr & Trainbr & Trainbr & Trainbr \\
\hline Hidden layer structure & {$[10]$} & {$[12]$} & {$[14]$} & {$[16]$} & {$[8]$} & {$\left[\begin{array}{ll}8 & 4\end{array}\right]$} & {$\left[\begin{array}{ll}10 & 6\end{array}\right]$} & {$\left[\begin{array}{lll}10 & 6 & 2\end{array}\right]$} & {$\left[\begin{array}{ll}7 & 3\end{array}\right]$} & [7] \\
\hline Number of epochs & 572 & 285 & 1000 & 331 & 504 & 437 & 683 & 1000 & 432 & 1000 \\
\hline Training $-R$ value & 0.99 & 0.98 & 0.99 & 1 & 0.98 & 1 & 0.98 & 0.99 & 0.98 & 0.42 \\
\hline Testing $-R$ value & 0.35 & 0.07 & 0.06 & -0.18 & 0.20 & 0.22 & 0.38 & 0.14 & 0.21 & 0.13 \\
\hline Overall $-R$ value & 0.75 & 0.61 & 0.59 & 0.47 & 0.74 & 0.51 & 0.69 & 0.68 & 0.74 & 0.35 \\
\hline
\end{tabular}

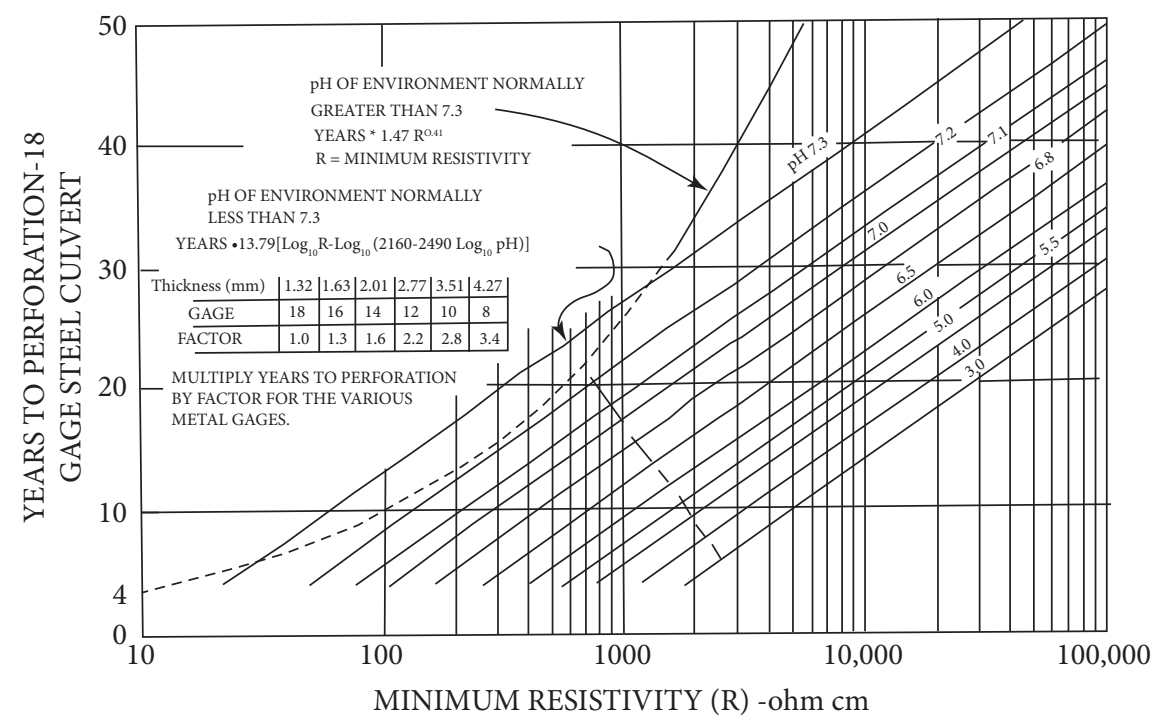

(a)

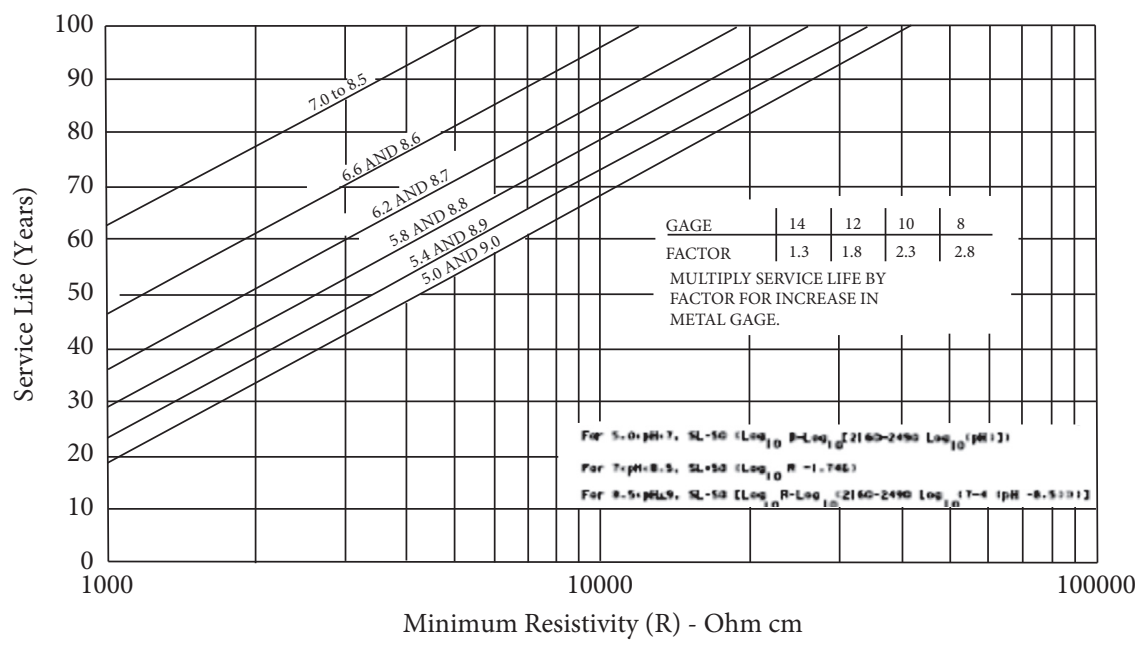

(b)

Figure 2: Continued. 


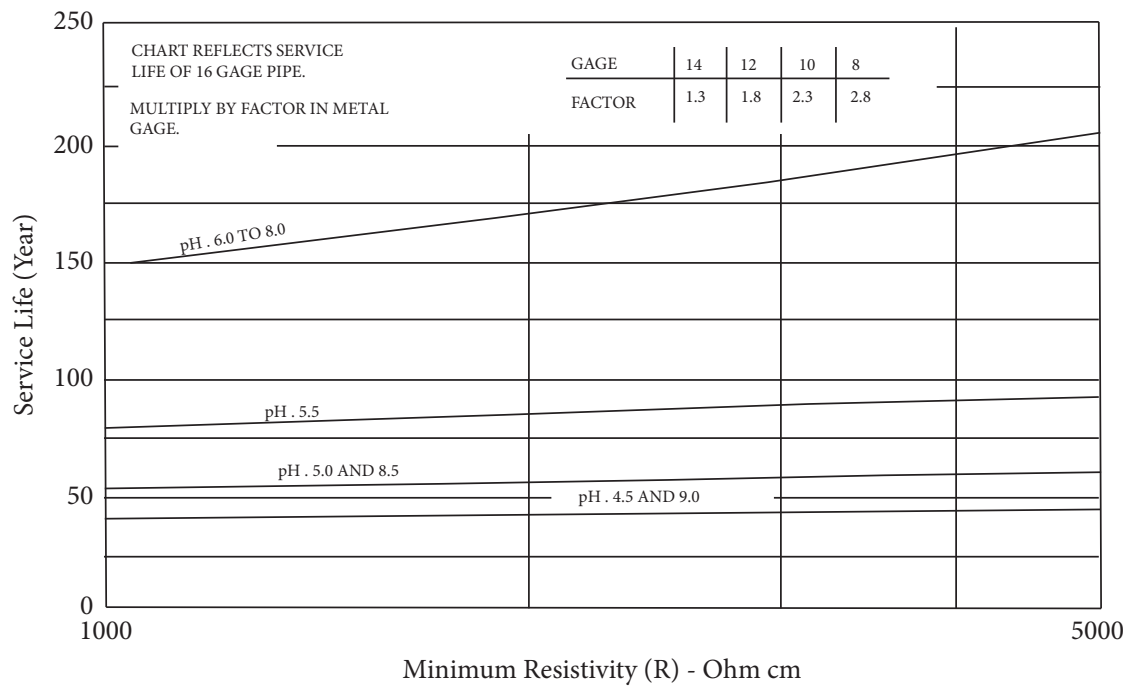

(c)

FIGURE 2: Graphical representation of service life estimation methods: (a) 1999 caltrans, (b) 2012 FDOT-aluminized steel, and (c) 2012 FDOT-aluminum.

deviation of 0.65 . After dividing all 334,102 Arkansas parishes into $250 \mathrm{~m} \times 250 \mathrm{~m}$ raster cells and allocating the same $\mathrm{pH}$ within a raster cell, the average $\mathrm{pH}$ of 2,137,685 raster cells was found to be 5.51 with a standard deviation of 0.77 . The average $\mathrm{pH}$ of surface water within the state varies from 1.5 to 10.28 , with an average of value 7.0 and a standard deviation of 0.83 . The average $\mathrm{pH}$ value of soils for each county is presented in Figure 3(a). This map shows that Union, Ouachita, Nevada, Grant, Saline, and Madison counties have $\mathrm{pH}$ values of less than 5, which are categorized as "highly acidic." Four other categories shown in the map are classified as "moderately acidic," with average $\mathrm{pH}$ values between 5 and 5.5, and "acidic," with $\mathrm{pH}$ values ranging from 5.5 to 6.0 . For $\mathrm{pH}$ ranging from 6.0 to 6.5 , the counties are considered as "mild acidic," and for $\mathrm{pH}$ values greater than 6.5 , the counties are considered as "not acidic."

3.2. Resistivity. As noted earlier, one of the main goals of this research is to evaluate the soil resistivity of different locations based on the existing secondary data and collected primary data. Using the secondary data collected from the USDA and laboratory investigation results, a neural network model was developed to predict the soil resistivity of parishes. The predicted average soil resistivity values of each county are plotted in Figure 3(b).

As seen in Figure 4, a few counties (Fulton, Sharp, Izard, Baxter, and Clay) in the northeastern part of Arkansas have low soil resistivity values. In the northwestern part of the state, Newton and Madison counties have very low soil resistivity values. On the western border of the state, three counties (Scott, Howard, and Perry) have very low soil resistivity. In the southern part of the state, two counties (Union and Nevada) have comparatively lower soil resistivity values compared to other counties under study. The rest of the counties in the eastern part have comparatively higher soil resistivity. Figure 4 shows that the upper basin of the White River has comparatively lower soil resistivity, and the lower basin, a part of the Arkansas River basin, and the Red River basin have comparatively higher soil resistivity. The results obtained based on the model show consistency with the geological map of Arkansas [13]. In general, the average value of soil resistivity of each county varies between 657 and $7698 \mathrm{ohm}-\mathrm{cm}$. For the entire state, the resistivity ranges from 7 to $22515 \mathrm{ohm}-\mathrm{cm}$. The average value of soil resistivity in Arkansas is $3524 \mathrm{ohm}-\mathrm{cm}$ with a standard deviation of $4034 \mathrm{ohm}-\mathrm{cm}$. On the other hand, the estimated water resistivity within the state ranges from 264 to $1,62,500$ ohm-cm with an average value of $9,156 \mathrm{ohm}-\mathrm{cm}$ and a standard deviation of $8,133 \mathrm{ohm}-\mathrm{cm}$.

\subsection{Estimated Service Life}

3.3.1. Plain Galvanized Steel Pipe (GSP). According to the California method (1993), the service life of plain GSP can be up to 50 years. This method uses resistivity and $\mathrm{pH}$ values of the surrounding media (soil and water) as key parameters, and the service life can be estimated based on the technique shown in Figure 2(a). The current study used the previouslydetermined soil resistivity values and extracted soil $\mathrm{pH}$, water $\mathrm{pH}$, and water resistivity values to estimate the service life GSP at each raster cell for a 16-gage pipe. The service life is estimated separately based on soil $\mathrm{pH}$ and resistivity and water $\mathrm{pH}$ and resistivity, then the lowest value is reported. For GSP, an estimated service life from 0 to 10 years has been considered as extremely corrosive, 10 to 20 years as highly corrosive, 20 to 30 years as moderately corrosive, 30 to 40 years as corrosive, and 40 to 50 years as mildly corrosive. Later, the estimated service lives were interpolated over the region. The interpolated GIS raster map for GSP is shown in Figure 4. From Figure 4 it is evident that most of the counties and districts are categorized as extremely corrosive to highly 


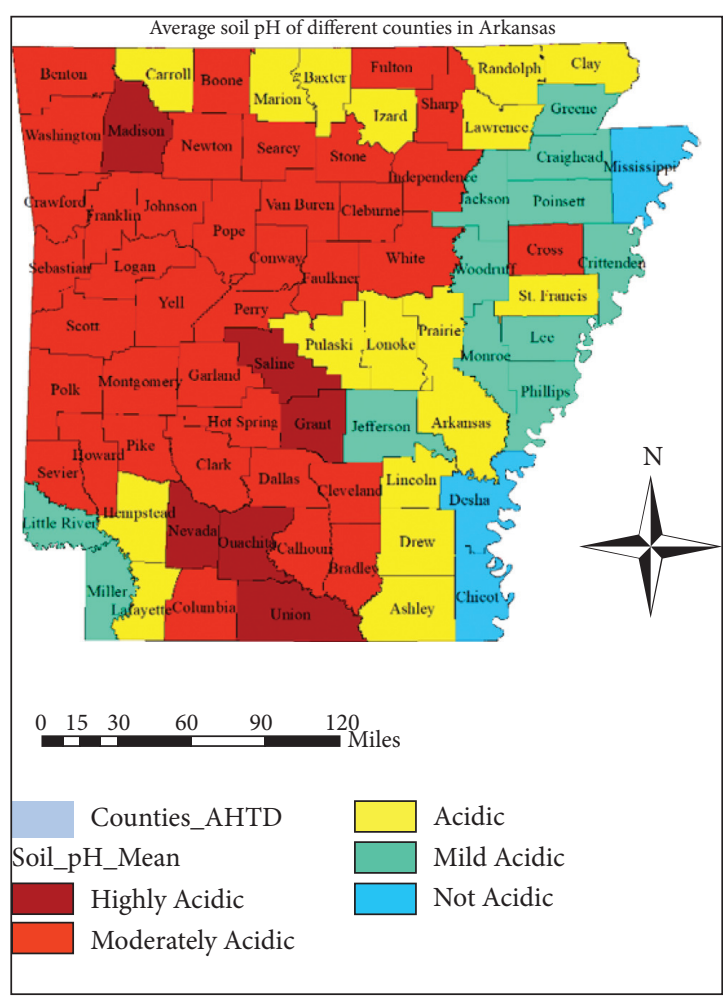

(a)

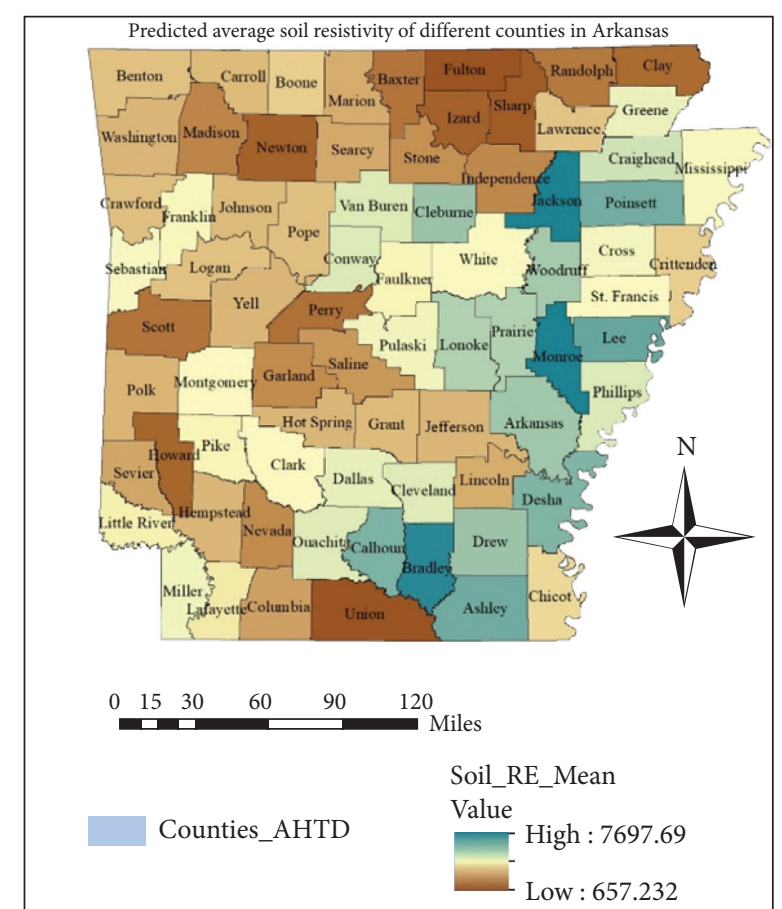

(b)

Figure 3: Average $\mathrm{pH}$ and resistivity of soils in different counties of Arkansas: (a) average soil pH and (b) average soil resistivity.

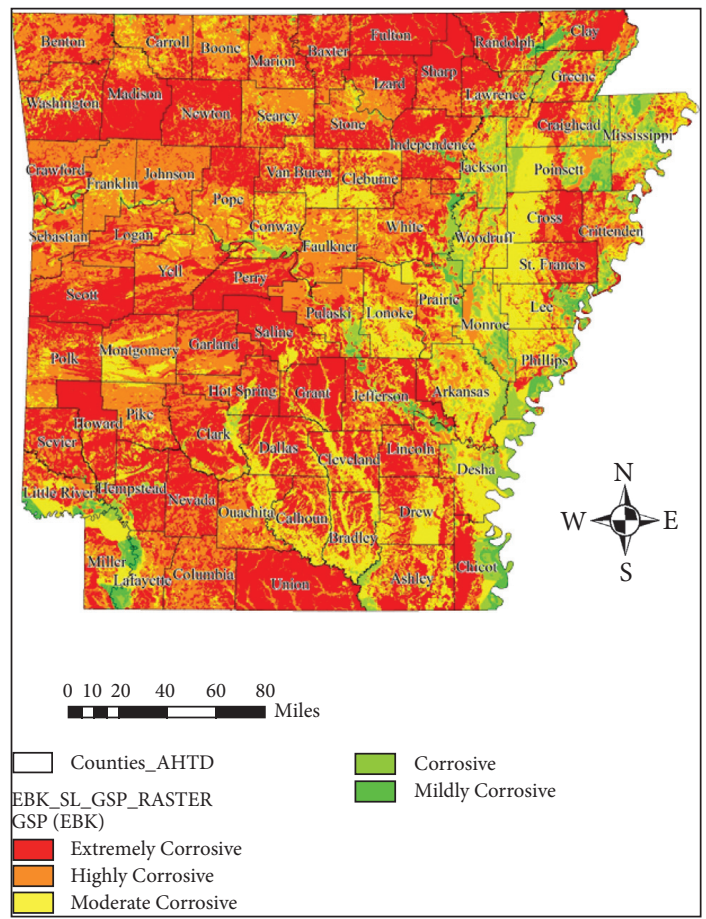

FIGURE 4: Galvanized steel pipe corrosion risk prediction map (generated using EBK).

corrosive for 16-gage GSPs. The service lives for different sizes of GSPs can be estimated by using multiplying factors of 1.6, 2.2, 2.8, and 3.4 for 14-gage, 12-gage, 10-gage, and 8- gage GSPs, respectively [9]. Based on Figure 4, only the GSPs located in the northeastern part of Arkansas have high expected service lives. In general, most of the parts of the 
state should be given careful thought before using any 16 and 18 gages GSPs. Any existing GSPs with 10 years of service or more should be checked as precautionary steps. For future development or construction projects, alternative pipe materials should be taken into consideration for achieving better service lives.

3.3.2. Aluminized (Type II) Corrugated Steel Pipe. While determining the service lives of aluminized (type II) corrugated steel pipes, the previously stated approaches of GSPs were used except that for the cases in which the FDOT method instead of the California method was followed. In the interpolated maps developed for this category of pipes, an estimated service life of 0 to 20 years was considered as extremely corrosive, 20 to 40 years as highly corrosive, 40 to 60 years as moderately corrosive, 60 to 80 years as corrosive, and more than 80 years as mildly corrosive. The interpolated map for aluminized (type II) corrugated steel pipe is shown in Figure 5. From Figure 5, it is evident that a significant portion of the state has moderate to mild corrosion risks, which indicate comparatively higher service lives compared to those of GSPs. However, in some parts of ARDOT Districts 2, 3, 4, 6, 7, and 9, this type of pipe is expected to have a very low service life. Thus, sufficient precautions should be taken to use this type of pipe in these regions. The raster maps shown in Figure 5 are for 16-gage pipes. For different sizes of aluminized (type II) corrugated steel pipes, the service lives can be estimated by using a multiplying factor. These multiplying factors are 1.3, 1.8, 2.3, and 2.8 for 14-gage, 12-gage, 10-gage, and 8-gage pipes, respectively [10].

3.3.3. Corrugated Aluminum Pipe. Similar to GSP and aluminized corrugated steel pipes, the service life of corrugated aluminum pipes is estimated based on the FODOT method. For this type of pipe, an estimated service life of 0 to 40 years was considered as extremely corrosive, 40 to 60 years as highly corrosive, 60 to 80 years as moderately corrosive, 80 to 100 years as corrosive, and more than 100 years as mildly corrosive. Even if the environment is extremely corrosive, this study showed that this type of metal pipe can survive for a very long period. However, the risk of abrasion is very high for this type of metal pipe. So, in the case of selecting this type of metal pipe, the type of sediments that pass through the pipes or culverts should be analyzed before any decisions are made. A detailed interpolated map of predicted service lives of corrugated aluminum type is shown in Figure 6. Figure 6 shows that except for some counties (Union, Logan, Grant, Newton, Lonoke, Independent, Washington, and Crawford), most of the state has soils that are categorized as less corrosive to this type of pipe. Similar to the other two types of pipes, a 16-gage pipe has been considered to evaluate the service life of this type of pipe. For different sizes of corrugated aluminum pipes, the service life can be extrapolated by using a multiplying factor according to the method in [10]. These multiplying factors are 1.3, 1.8, 2.3 and 2.8 for 14-gage, 12-gage, 10gage, and 8 -gage aluminum pipes, respectively.

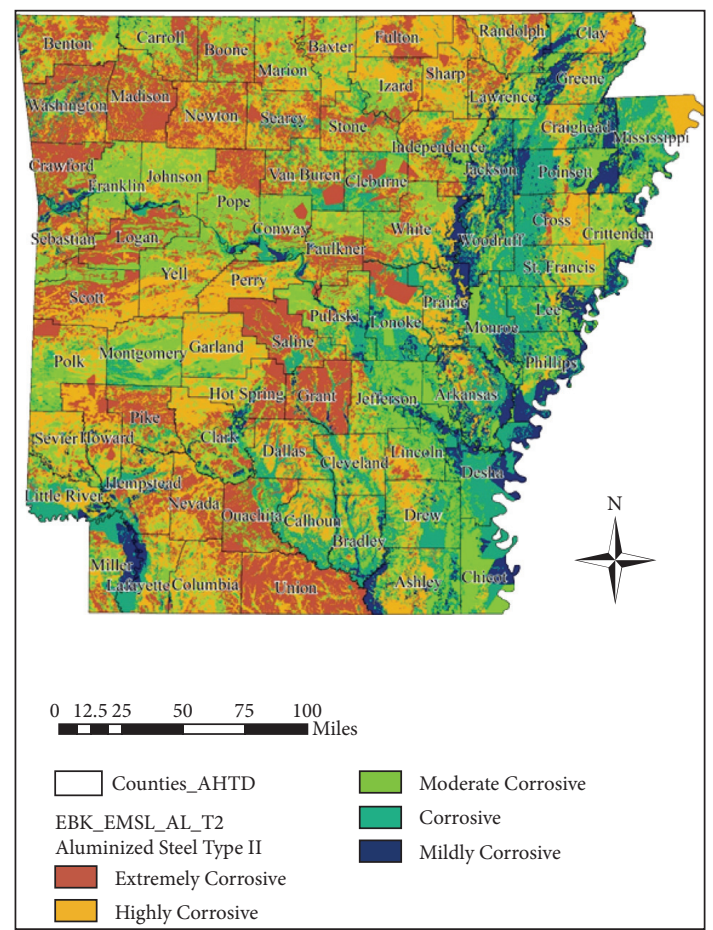

Figure 5: Aluminized steel (type II) pipe corrosion risk prediction map (generated using EBK).

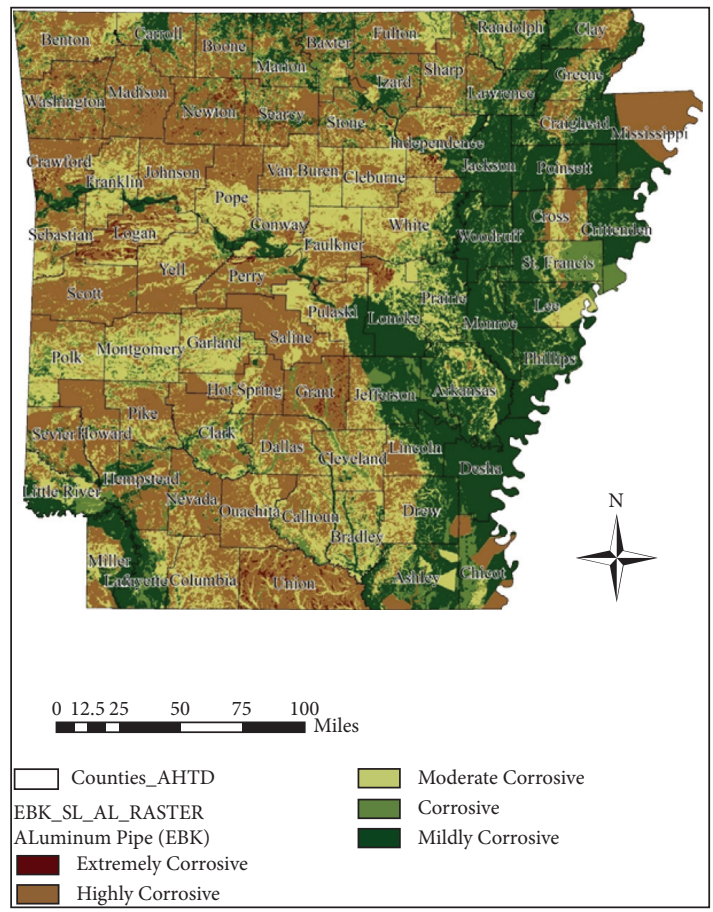

FIgURE 6: Aluminum pipe corrosion risk prediction map (generated using EBK).

\section{Conclusions}

The main objective of this study was to evaluate the corrosion risk of metal pipes and develop corrosion risk maps for the state of Arkansas. This study has identified the useable secondary data sources and analyzed the available datasets along with 
laboratory-based experimental results. Important geotechnical and geochemical properties of soil and water quality data were collected for all 75 counties of Arkansas. Several soil samples were also collected from different locations in the state. Based on the experimental results and collected data from the public domain, a neural network (NN) based model was developed to predict soil resistivity. The water quality data were collected from the ADEQ. Combined soil $\mathrm{pH}$, soil resistivity, surface water $\mathrm{pH}$, water resistivity parameters, and the expected service lives of three types of predominately used metal pipes (plain galvanized steel, aluminized steel, and aluminum) in Arkansas were estimated using the California and FDOT methods. The EBK interpolation method was applied for developing the GISbased maps that estimate the probable service lives of the three metal types of 16-gage pipes. In general, aluminized corrugated steel pipe or aluminum pipes were found to last longer than galvanized steel pipes. However, the service lives of any of these types of metal pipes varied significantly when they were to be installed in different construction sites within Arkansas. The estimated service lives presented in the maps can be used to extrapolate the service lives of different sizes (gage thicknesses) and other types of metal such as coated pipes.

The findings of this study are implementation-ready and can be immediately used by ARDOT engineers for selecting appropriate metal pipes and maintaining highway drainage pipes. The practice of using these maps will help avoid any unwanted accidents by selecting unsuitable metal pipes in critical areas shown in the maps. Therefore, it is expected to reduce the unnecessary costs associated with the removal and/or replacement of metal culverts. The findings of this study will also help the agency to estimate the condition of the existing culverts installed at critical locations and can be used as a guide for taking the necessary measures to reduce extra expenditure. The developed neural network model can be used for estimating soil resistivity, based on existing secondary data in any location.

One of the limitations of this study is the incorporation of the abrasion levels in the model since they are not easily quantifiable at different locations based on the available sediment data found in the United States Geological Survey database. Therefore, precautions should be taken in selecting aluminum pipes in which abrasion levels play a critical role in determining the service life. The developed neural network model can be updated when new investigation results and additional secondary data are available.

\section{Data Availability}

All the data, models, or codes that support the findings of this study are available from the corresponding author upon reasonable request.

\section{Conflicts of Interest}

The authors declare that they have no conflicts of interest.

\section{Acknowledgments}

The authors would also like to thank District 02 (Mr. Brad Smithee) and District 10 (Mr. Deric Wyatt) engineers for their effort and assistance in collecting soil samples and providing preliminary data. The technical assistance of Ms. Jami Nash, Mr. Alan Copelin, Dr. Shubhalaxmi Kher, and Dr. Ashraf Elsayed, all from A-State, throughout the project is highly recognized. The authors would also like to thank the other members of the research team at A-State including Mr. Sumon Roy, Ms. Sara Ford, and Ms. Paige Leissner. The authors would like to thank the Transportation Consortium of South-Central States (Tran-SET) for providing funds and technical support to conduct this study.

\section{References}

[1] Arkansas Department of Transportation (Ardot), "Unit price for projects awarded to contract," 2019, https://www. arkansashighways.com/ProgCon/General/bid_tabs_include. aspx.

[2] U.S. Department of Agriculture (USDA), "National soil survey handbook, title 430-VI," 2018, http://www.nrcs.usda. gov/wps/portal/nrcs/detail/soils/ref/?cid=nrcs142p2_054242.

[3] M. Hasan and Z. Hossain, "An overview of corrosion risk of metal culverts in Arkansas," in Proceedings of the 2019TranSET Conference, San Antonio, TX, USA, April 2019.

[4] S. Tewari and F. Manning, "Spatial delineation of corrosion zones for metal culverts based on coastal louisiana soil characteristics," in Proceedings of the Transportation Research Board 97th Annual Meeting, Washington D.C, USA, January 2018.

[5] M. Maher, G. Hebeler, and A. Fuggle, Service Life of Culverts-A Synthesis of Highway Practice, Synthesis 474, National Cooperative Highway Research Program, Washington, D.C, USA, 2015.

[6] Natural Resources Conservation Service (NRCS), "Web soil survey," 2018, https://websoilsurvey.nrcs.usda.gov/.

[7] Arkansas Department of Environmental Quality (ADEQ), "Water quality monitoring data, laboratory and monitoring services," 2018, https://www.adeq.state.ar.us/techsvs/env_ multi_lab/water_quality_station.aspx\#Display.

[8] Y. Erzin, B. H. Rao, A. Patel, S. D. Gumaste, and D. N. Singh, "Artificial neural network models for predicting electrical resistivity of soils from their thermal resistivity," International Journal of Thermal Sciences, vol. 49, no. 1, pp. 118-130, 2010.

[9] Department of Transportation (Caltrans), Method for Estimating the Service Life of Steel Culverts, Caltrans, Sacramento, CA, USA, 1999.

[10] Florida Department of Transportation (Fdot), Drainage Manual-Optional Pipe Material Handbook. Drainage Section, Office of Design, FDOT, Tallahassee, FL, USA, 2012.

[11] American Iron and Steel Institute (AISI), Handbook of Steel Drainage and Highway Construction Products, AISI, Washington, D.C, USA, 5th edition, 1994.

[12] A. F. Rusydi, "Correlation between conductivity and total dissolved solid in various type of water: a review," IOP Conference Series: Earth and Environmental Science, vol. 118, no. 1, Article ID 012019, 2018.

[13] Arkansas Geological Survey (Ags), Geologic Map of Arkansas, Geologic Maps, AGS, https://www.geology.arkansas.gov/docs/ pdf/maps-and-data/geologic_maps/geologic-map-of-arkansas1993-(34x52).pdf, 1993. 